Article

\title{
Remote Sensing Applied to the Study of Fire Regime Attributes and Their Influence on Post-Fire Greenness Recovery in Pine Ecosystems
}

\author{
Víctor Fernández-García ${ }^{1, *}{ }^{(\mathbb{D}}$, Carmen Quintano ${ }^{2}$, Angela Taboada ${ }^{1}$ () , Elena Marcos ${ }^{1}$, \\ Leonor Calvo $^{1}$ (iD) and Alfonso Fernández-Manso ${ }^{3}$ \\ 1 Area of Ecology, Department of Biodiversity and Environmental Management, \\ Faculty of Biological and Environmental Sciences, Universidad de León, 24071 León, Spain; \\ angela.taboada@unileon.es (A.T.); elena.marcos@unileon.es (E.M.); leonor.calvo@unileon.es (L.C.) \\ 2 Electronic Technology Department, Sustainable Forest Management Research Institute, \\ Universidad de Valladolid, Spanish National Institute for Agriculture and Food Research and \\ Technology (INIA), C/Francisco Mendizábal s/n, 47014 Valladolid, Spain; menchu@tele.uva.es \\ 3 Agrarian Science and Engineering Department, Universidad de León, Av. Astorga s/n, \\ 24400 Ponferrada, Spain; alfonso.manso@unileon.es \\ * Correspondence: vferg@unileon.es
}

Received: 5 April 2018; Accepted: 7 May 2018; Published: 9 May 2018

\begin{abstract}
We aimed to analyze the relationship between fire regime attributes and the post-fire greenness recovery of fire-prone pine ecosystems over the short (2-year) and medium (5-year) term after a large wildfire, using both a single and a combined fire regime attribute approach. We characterized the spatial (fire size), temporal (number of fires, fire recurrence, and return interval), and magnitude (burn severity of the last fire) fire regime attributes throughout a 40-year period with a long-time series of Landsat imagery and ancillary data. The burn severity of the last fire was measured by the dNBR (difference of the Normalized Burn Ratio) spectral index, and classified according to the ground reference values of the CBI (Composite Burn Index). Post-fire greenness recovery was obtained through the difference of the NDVI (Normalized Difference Vegetation Index) between pre- and post-fire Landsat scenes. The relationship between fire regime attributes (single attributes: fire recurrence, fire return interval, and burn severity; combined attributes: fire recurrence-burn severity and fire return interval-burn severity) and post-fire greenness recovery was evaluated using linear models. The results indicated that all the single and combined attributes significantly affected greenness recovery. The single attribute approach showed that high recurrence, short return interval and low severity situations had the highest vegetation greenness recovery. The combined attribute approach allowed us to identify a wider variety of post-fire greenness recovery situations than the single attribute one. Over the short term, high recurrence as well as short return interval scenarios showed the best post-fire greenness recovery independently of burn severity, while over the medium term, high recurrence combined with low severity was the most recovered scenario. This novel combined attribute approach (temporal plus magnitude) could be of great value to forest managers in the development of post-fire restoration strategies to promote vegetation recovery in fire-prone pine ecosystems in the Mediterranean Basin under complex fire regime scenarios.
\end{abstract}

Keywords: Pinus pinaster; number of fires; fire size; fire recurrence; fire return interval; burn severity; dNDVI 


\section{Introduction}

Forest fires are the predominant disturbance in many regions of the world [1,2]. This is the case in the Mediterranean Basin, where fire has a significant effect on the functioning and structure of ecosystems [3,4]. In this area, forests most affected by fire are the fire-prone pine ecosystems [5], whose species have developed different fire-adaptive strategies to facilitate post-fire survival or reproduction [6-8].

The role of fire in fire-prone pine ecosystems can be characterized by describing the fire regime [6]. The term fire regime integrates spatial, temporal, and magnitude attributes [9-11]. Among the spatial attributes, fire size can hinder the regeneration of vegetation, especially in those ecosystems whose regeneration is not completely dependent on endogenous processes, and therefore depends on seed dispersal from nearby unburned areas [2]. Temporal attributes include fire recurrence and fire return interval, which are important driving factors of the structure and composition of Mediterranean ecosystems [12-14], as well as of their post-fire regeneration capacity. Fire recurrence, is considered as the number of fires that occurred in a given period [8]. High fire recurrences can reduce the ability of some species to recover, especially obligate seeders [2,15], such as the endemic pine species of the Mediterranean Basin [6,7], whereas other species, including resprouter shrubs, can be promoted by recurrent fires $[3,16]$. On the contrary, the fire return interval is defined as the time lapse between fires [10]. In most fire-prone Mediterranean ecosystems, auto-succession is expected when fire return intervals are longer than the period required by plants for regeneration or maturation [8]. Therefore, the fire return interval can be a determinant parameter in the recovery of ecosystems that need long periods to achieve maturity. This is the case of many pine ecosystems in the Mediterranean Basin, whose dominant tree species need up to 15 years to achieve maturity or to produce a large seed bank ensuring post-fire recruitment $[7,17,18]$. The magnitude attributes include burn severity [10], considered as the loss of or change in ecosystem biomass [19], and linked to the ecosystem response after disturbances $[14,18,20]$. Burn severity is a frequently used metric because it can be quantified after fire [21]. Therefore, the knowledge of the spatial patterns of fire regime attributes in large wildfires can contribute to understanding the ecosystem structure [10] and post-fire dynamics [20,22,23]. Consequently, this information is of great interest for managers to promote ecosystem resiliency [24], and to design adequate post-fire restoration strategies.

In the Mediterranean Basin, land use changes that occurred during the last decades have resulted in increases of fuel continuity, which are facilitating the occurrence of a high number of large wildfires (>500 ha) $[4,25]$. As a consequence, burned areas are increasingly larger and highly heterogeneous, making it difficult to study the spatial patterns of fire regime attributes through field work, and therefore remote sensing methods are essential [3]. The starting point to define the spatial and temporal attributes of a fire regime, such as fire size, fire recurrence, and fire-return interval, is the mapping of fire scars $[10,24]$. The moderate-resolution sensors on board Landsat satellites have been largely employed for fire scar mapping [26-28]. Landsat missions have the advantage of providing multispectral imagery for a long historical period (since 1972) [29]. An easy and reliable way to discriminate burned areas using Landsat imagery is through a visual analysis of subsequent Landsat scenes [28,30,31]. In addition, Landsat imagery is the most used source of information to map burn severity [19] through the standard spectral index dNBR (difference of the Normalized Burn Ratio) [32]. The dNBR uses pre- and post-fire information provided by the Near Infrared, which is sensitive to changes in canopy density and the cellular structure of plant leaves, and the information provided by the Short Wave Infrared, which is primarily related to moisture content [33]. Although the performance of dNBR has been validated repeatedly in the literature [33-35], it is convenient to calibrate its thresholds in each specific fire to generate meaningful categorical maps [36,37]. The validation and thresholds calibration of dNBR is traditionally done through the CBI (Composite Burn Index) [36], a field index that integrates several burn severity metrics visually estimated of five vertical strata.

To date, there are many studies determining the influence of a single fire regime attribute on post-fire recovery (e.g., [38,39]), but we did not find studies accomplishing a full approach 
integrating the spatial, temporal, and magnitude fire regime attributes using remote sensing methods. This integrated approach is of great interest in fire-prone ecosystems, because some fire regime attributes can interact among them and produce synergistic effects on ecosystems [40,41]. For instance, field studies have suggested that high severities might hinder post-fire recovery, especially in forest systems adapted to recurrent, low severity fires [41,42]. Conversely, other authors have suggested that the most harmful fires could be those with a long-return interval affecting forests prone to high severity fires [23]. The expected influence of the joint effect of temporal (fire recurrence and fire return interval) and magnitude (burn severity) fire regime attributes on post-fire vegetation recovery suggests the need to merge these parameters in more realistic combined fire regime attribute categories. Using this novel combined attribute approach could therefore be very useful in studies on post-fire recovery capacity under different real-world fire regime scenarios, allowing the identification of critical burned areas where regeneration could be endangered and require post-fire management actions.

Beyond the fire regime characterization, Landsat imagery can be used to assess post-fire vegetation recovery $[8,43,44]$, which is defined as the ecological process aimed at reverting to pre-fire status [23]. Remote sensing methods to quantify post-fire regeneration include the analysis of vegetation greenness through spectral indices. In this case, the Normalized Difference Vegetation Index (NDVI), proposed by Rouse [45], has become accepted as the standard index [23,27,38,39,46]. The NDVI index is highly sensitive to canopy cover and photosynthetic activity by combining Near Infrared reflectance and the Red reflectance [46]. Thus, on the landscape scale, the NDVI is a reasonable proxy for green biomass, providing an overall idea of the vegetation greenness recovery independently of the plant species [47].

The aim of this study is to analyze how vegetation greenness responded to fire regime attributes in pine ecosystems in an area where wildfires are very frequent, both over the short (2 years) and medium (5 years) term after the most recent large wildfire, using a remote sensing approach. Specifically, we intend to (I) characterize the spatial, temporal, and magnitude fire regime attributes affecting the fire-prone pine ecosystems in the study area over a 40-year period, (II) determine the post-fire recovery of vegetation greenness in pine ecosystems, and (III) analyze the relationship between the characterized fire regime attributes and greenness recovery over the short and medium term after fire, using both a single and a combined fire regime attribute approach. We expected that, relative to the single attribute analysis, the novel combined attribute approach would enable the identification of the most favorable situations for vegetation greenness recovery under complex fire regime scenarios.

\section{Material and Methods}

\subsection{Study Area}

The study was conducted within the perimeter of the large wildfire that occurred on 19 August 2012 in Sierra del Teleno (León Province, NW Iberian Peninsula) (Figure 1), a mountain range largely affected by wildfires [48].

The wildfire scar is an area of $119 \mathrm{~km}^{2}, 103 \mathrm{~km}^{2}$ of which were formerly occupied by Pinus pinaster Ait. ecosystems (Figure 1). The P. pinaster population of Sierra del Teleno is adapted to a severe crown fire regime, bearing a high percentage of serotinous cones [7]. However, due to increased fire recurrence in recent decades [48], P. pinaster forests are turning into successional shrublands dominated by Pterospartum tridentatum (L.) Willk., Halimium lasianthum (Lam.) Spach and Erica australis L. [22], as in many areas in the Western Mediterranean Basin [14]. The orography is heterogeneous, ranging from 836 to 1493 m.a.s.l. Soils are acidic (4.86 \pm 0.14 ; mean \pm standard error $\mathrm{pH})$, developed over siliceous lithologies such as quartzite, conglomerate, sandstone, and slate [49]. The study area is on the limit of the Mediterranean region, whose climate is classified as temperate with dry and temperate summers [50], and characterized by a mean annual precipitation of between 600 and $800 \mathrm{~mm}$ and a mean annual temperature of $8-11^{\circ} \mathrm{C}[51]$. 

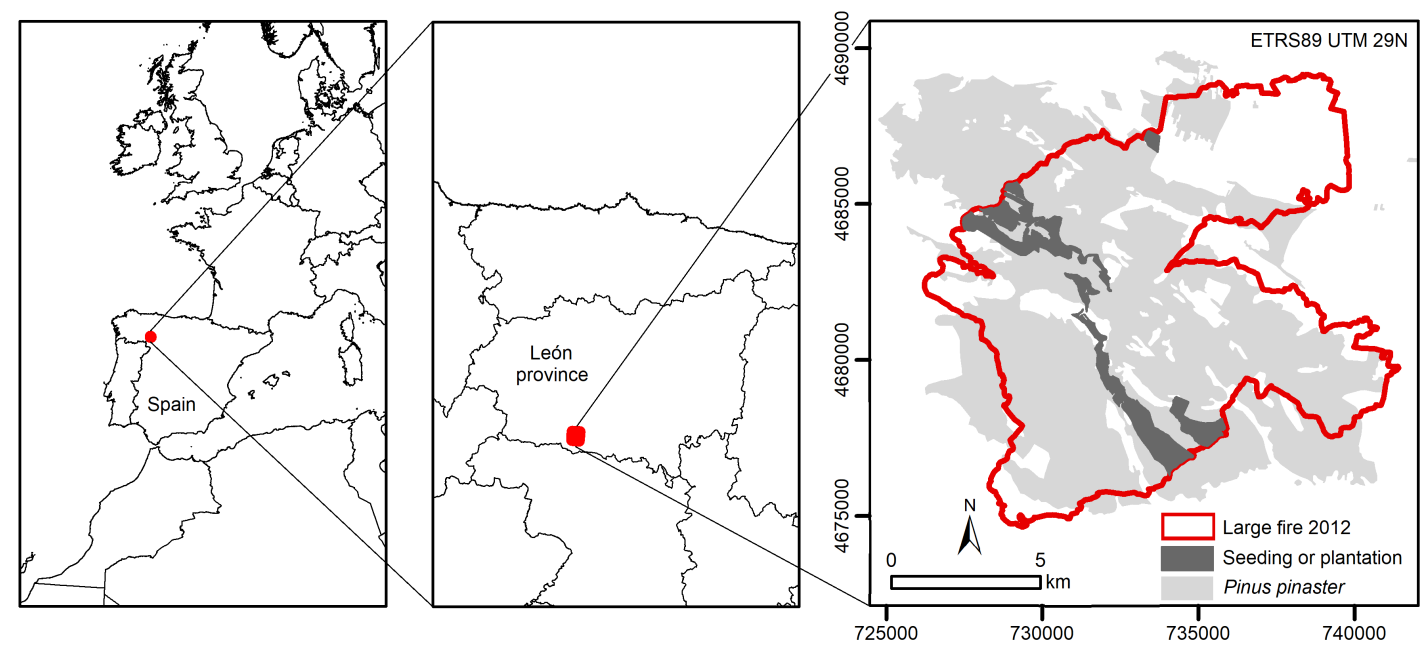

Figure 1. Location of the study area. The perimeter of the large wildfire that occurred in 2012, the natural occurrence of Pinus pinaster, and post-fire management actions applied after the large fire of 2012 are indicated.

\subsection{Methodology}

\subsubsection{Landsat Database}

In order to characterize (a) the spatial (average fire size), temporal (number of fires, fire recurrence, and fire return interval), and magnitude (burn severity) attributes of the fire regime, and (b) the post-fire recovery of vegetation greenness 2 (short term) and 5 (medium term) years after the 2012 large wildfire, we built a database composed of 80 Landsat images, covering the period 1975-2017 (Figure 2). The scenes before 1978 were used as a reference to identify the wildfires that occurred between 1978 and 1980. When available, at least one annual image of the study area without clouds was included in the database, with preference for those taken in late summer. The database encompassed images from the Landsat 2 (MSS sensor), Landsat 4 (TM sensor), Landsat 5 (TM sensor), Landsat 7 (ETM + sensor), and Landsat 8 (OLI sensor) satellites. The images for 1975-1990 and 1999-2017 were obtained from the Earth Explorer server of the U.S. Geological Survey (https: / / earthexplorer.usgs.gov), whereas those for 1991-1998 were acquired from the European Space Agency (https:/ / earth.esa.int).

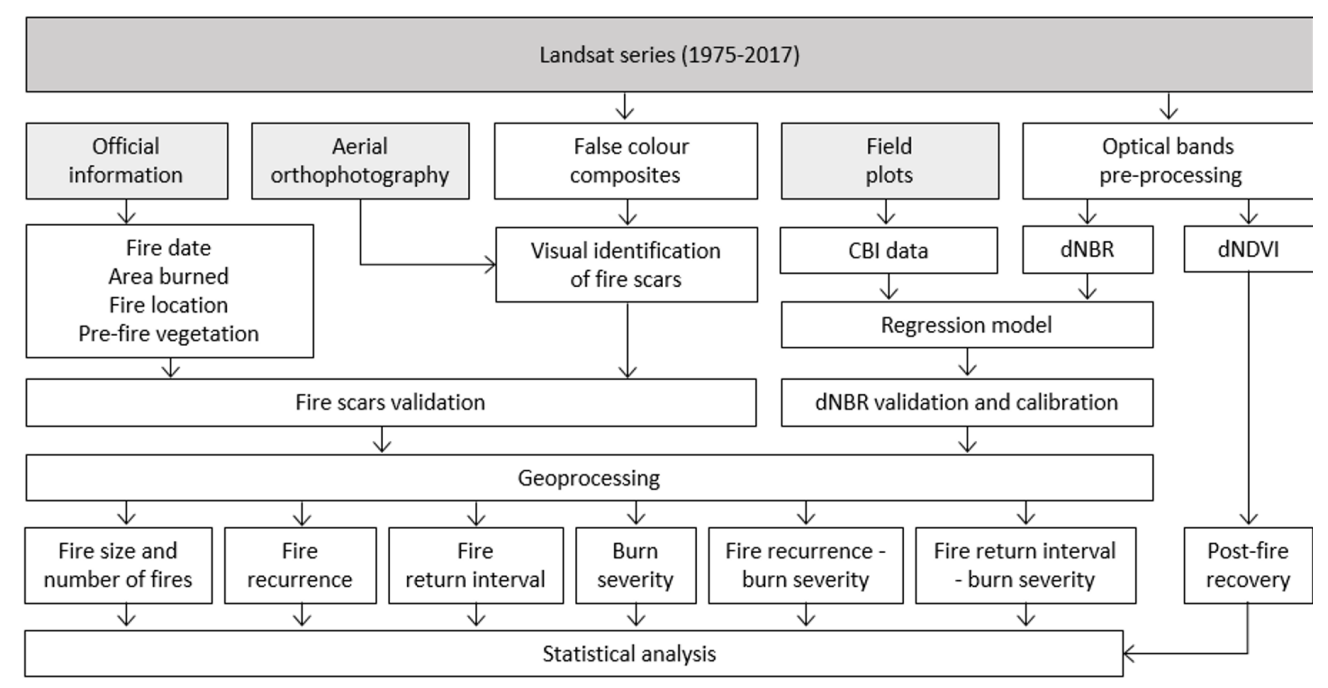

Figure 2. Methodology flowchart. 


\subsubsection{Fire Regime Characterization}

Fire scars from the wildfires that occurred between 1978 and 2017 were identified by visual analysis of consecutive Landsat false color composites (Figure 2). We displayed the false color composite RGB 564 for the images obtained by the MSS sensor, RGB 541 for the TM and ETM + sensors, and RGB 652 for the OLI sensor. Orthophotography from 1980 taken by the National Institute for Agrarian Reform and Development flight (1977-1983) was used as ancillary data to identify fire scars during a period with low availability of Landsat images, as well as to support the MSS imagery, which has a lower spatial resolution $(60 \mathrm{~m})$. The perimeters of every wildfire were manually digitized using a scale of 1:5000 in ArcMAP 10.6 [52]. The minimum mapping unit used for hand drawing was $0.01 \mathrm{~km}^{2}$, as this is the limit between an incipient fire and a wildfire according to the Spanish Administration classification [53], and because it surpasses the minimum identifiable fire size using imagery from TM sensors and later [54]. In order to ensure that the digitized scars were the consequence of wildfires, and not the result of other potential land uses (e.g., ploughing, cutting, clearcutting, etc.), we linked every digitized perimeter to an official wildfire report (1978-2017) provided by the Nature Protection Section of the Regional Administration, which included information on the fire date, location, extent, and burned vegetation for the entire study period, and also fire perimeters after 2007. All wildfires recorded by the official reports were matched with the fire perimeters mapped by the authors. The validated map of the fire scars from 1978 to 2017 was the source of information to determine the following: (i) the total number and average size of the wildfires in each decade (1978-1987, 1988-1997, 1998-2007, and 2008-2017), (ii) wildfire recurrence during the study period by classifying the study area into low (1 fire), moderate ( 2 fires), and high ( $\geq 3$ fires) recurrence, and (iii) the fire return interval as the number of years between the 2012 large wildfire and the preceding fire, by classifying the study area into short (years $\leq 15)$, intermediate $(15<$ years $\leq 30$ ) and long (years $>30$ ) return intervals.

In order to characterize the burn severity of the 2012 large wildfire that occurred in 19 August, we calculated the dNBR spectral index [32] from the Landsat 7 ETM+ scenes of 20 September 2011 (pre-fire situation) and 6 September 2012 (post-fire). The Landsat 7 ETM+ scenes obtained are a Digital Numbers $(\mathrm{DN})$ product geometrically rectified and radiometrically corrected (Landsat L1T processing level). The scenes were subset and optical bands were pre-processed (Figure 2). Pre-processing included a conversion of $\mathrm{DN}$ to radiance values. Then, radiance images were atmospherically corrected by using the Fast Line-of-sight Atmospheric Analysis (FLAASH) module. To select the appropriate atmosphere model and input parameters in FLAASH, we used the MODIS water vapor product (MOD05), meteorological data (NOAA), and mean elevation values according to [33]. A Delaunay interpolation was applied to fill the gaps of the Scan Line Corrector (SLC) [55]. Corrected bands were used to calculate the dNBR index according to the following formulas:

$$
\begin{gathered}
\text { NBR }=(\varrho 4-\varrho 7) /(\varrho 4+\varrho 7) \\
\text { dNBR }=(1000(\text { NBRpre }- \text { NBRpost }))-\text { offset }
\end{gathered}
$$

where " $Q$ " is the reflectance of each specific corrected band and "offset" is the average index value in unchanged areas outside the fire perimeter, to account for differences in phenology between Landsat scenes [32]. For the offset calculation, we selected P. pinaster ecosystems unburned for the last 40 years, and less than $1.5 \mathrm{~km}$ from the fire scar, in which we randomly sampled 78 pixels ( $1 \%$ of the area that met these specifications).

The performance of the burn severity spectral index (dNBR) was field-validated with the ground reference CBI by performing linear regression models and examining the statistical significance and coefficient of determination $\left(R^{2}\right)$ of the relationship. To determine burn severity in the field we randomly established $54,30 \mathrm{~m} \times 30 \mathrm{~m}$ plots in the P. pinaster ecosystem within the first three months after the 2012 large wildfire. The positions of all field plots were GPS recorded. In each field plot we calculated burn severity following a CBI-based protocol described in [33], in which several variables of five vertical strata are rated, obtaining a final ground burn severity value ranging from 0 (unburned) to 
3 (high severity). Following [56], we established two burn severity categories: low-moderate (hereafter low severity) $(\mathrm{CBI} \leq 2.25)$ and high $(\mathrm{CBI}>2.25)$, and used the linear models to calibrate the dNBR thresholds according to the CBI values obtained in the field.

We then combined the temporal (fire recurrence and fire return interval) and magnitude (burn severity of the 2012 large wildfire) fire regime attributes and spatially analyzed the extent of each of the following combinations: (i) fire recurrence ( 3 classes) and burn severity ( 2 classes), and (ii) fire return interval ( 3 classes) and burn severity ( 2 classes).

\subsubsection{Post-Fire Greenness Characterization}

The post-fire recovery of vegetation greenness after the 2012 large wildfire was evaluated as the difference of the Normalized Difference Vegetation Index (dNDVI) [38,57] 2 (short term) and 5 (medium term) years after the fire (Figure 2). We selected the Landsat 7 ETM+ scenes from 20 September 2011 (pre-fire situation), 27 August 2014 (short term) and 20 September 2017 (medium term). Optical bands were subset and pre-processed equally as for dNBR calculation. Corrected bands were used to calculate the dNDVI index according to the following formulas:

$$
\begin{gathered}
\text { NDVI }=(\varrho 4-\varrho 3) /(\varrho 4+\varrho 3) \\
\mathrm{dNDVI}=(\text { NDVIpre }- \text { NDVIpost })-\text { offset }
\end{gathered}
$$

where " $Q$ " is the reflectance of each specific band, and "offset" is the average index value in unchanged areas outside the fire perimeter to account for differences in phenology between Landsat scenes [32]. For the offset calculation, we selected P. pinaster ecosystems unburned for the last 40 years, and less than $1.5 \mathrm{~km}$ from the fire scar, in which we randomly sampled 78 pixels ( $1 \%$ of the area that met these specifications). dNDVI values $\leq 0$ indicate the full recovery of vegetation greenness.

\subsubsection{Sampling}

The categories of fire regime attributes and values of post-fire greenness recovery were extracted using a random sampling design with a minimum distance between sample points of $60 \mathrm{~m}$ (two Landsat 7 ETM+ pixels). We distributed 932 sample points within the 2012 fire scar, in the area formerly dominated by P. pinaster ecosystems where no post-fire management actions were accomplished (Figure 1), excluding paths and the Landsat SLC failure zones. The same procedure was repeated in unburned areas adjacent $(<1.5 \mathrm{~km})$ to the fire perimeter (i.e., unburned P. pinaster ecosystems for at least 40 years), distributing 78 sample points. The number of sampling points corresponds to $1 \%$ of Landsat pixels of the burned and unburned areas with the specified characteristics [58].

\subsection{Data Analysis}

In order to analyze the effects of the single and combined fire regime attributes (fire recurrence, fire return interval, burn severity, fire recurrence-burn severity, and fire return interval-burn severity; categorical explanatory variables) on vegetation greenness (dNDVI 2 and 5 years after the fire; continuous response variables), we performed linear models (LMs) on which we conducted an Analysis of Variance (ANOVA) with pairwise multiple comparison of means (Tukey HSD). The goodness of fit of the models was assessed by visual analysis of homoscedasticity and normality of the residuals. Global spatial autocorrelation in the model residuals was checked using Moran's index $(I)$, indicating that it had no effect on the study results (Moran's $I<|0.1|$ ) [59].

All data analyses were carried out with R software, version 3.4.0 [60], using the "spdep" package [61]. 


\section{Results}

\subsection{Fire Regime Attributes}

We identified a total of 28 wildfires (size $\geq 0.01 \mathrm{~km}^{2}$ ) between 1978 and 2017 combining Landsat imagery and ancillary data (Figure 3). There were no fires subsequent to the 2012 large wildfire. In the last two decades (1998-2007 and 2008-2017), there was a decrease in the number of fires, and an increase in fire extent, reaching an average fire size of $29.74 \mathrm{~km}^{2}$ during 2008-2017 (Figure 4).

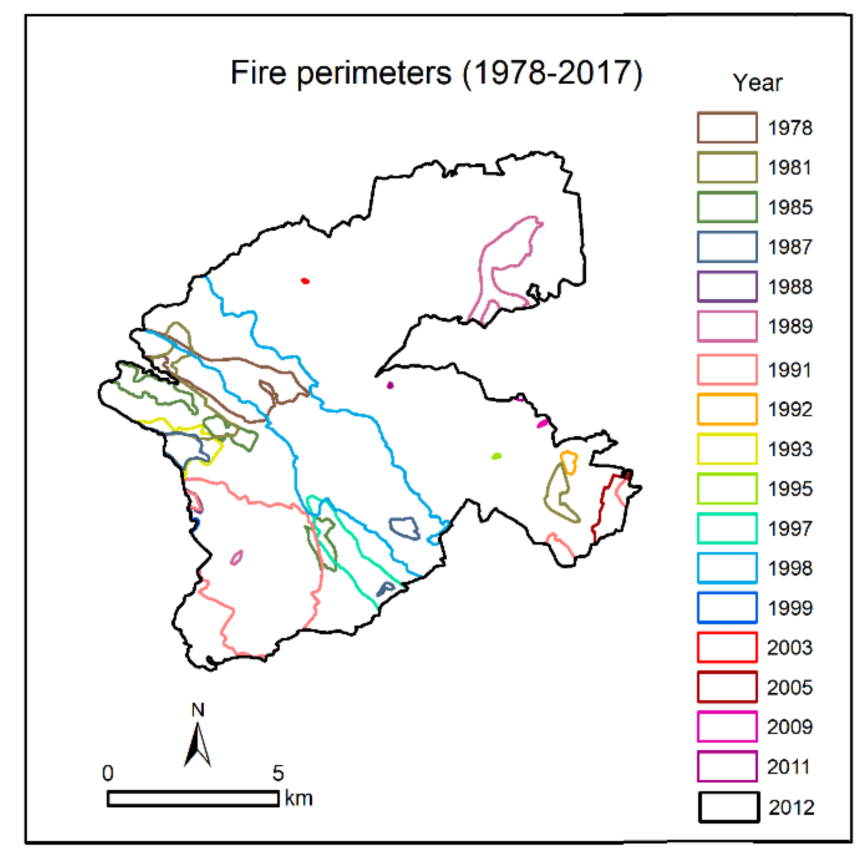

Figure 3. Fire perimeters and year of wildfire occurrence from 1978 to 2017.

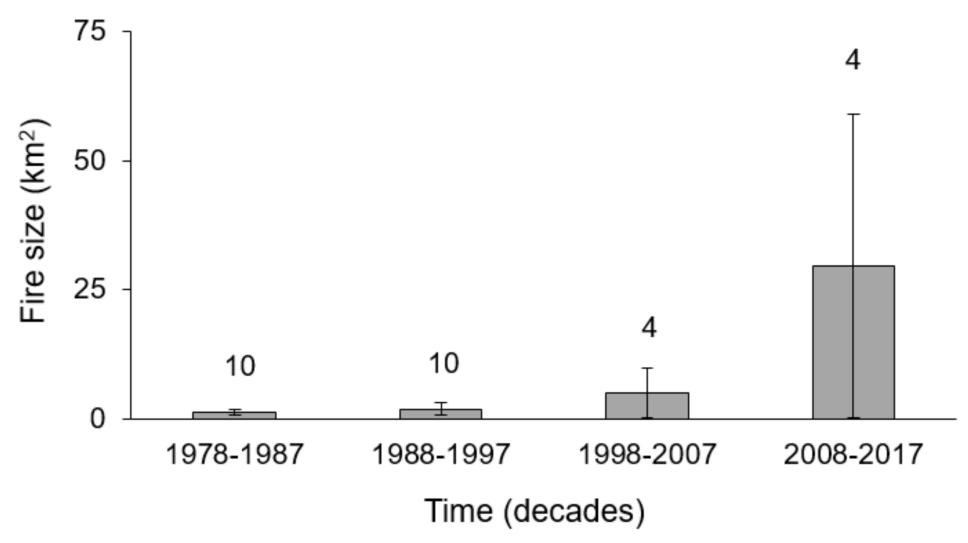

Figure 4. Average ( \pm standard error) size of wildfires by decade from 1978 to 2017 within the study area (the fire scar of the 2012 large wildfire). Numbers above bars indicate the total number of wildfires in each period.

The majority of the study area $\left(70.95 \mathrm{~km}^{2}\right)$ has not experienced any other fire prior to the large wildfire that occurred in 2012, and therefore was classified in the low fire recurrence category (1 wildfire from 1978 to 2017) (Figure 5a) and long fire return interval (>30 years) (Figure 5b). 

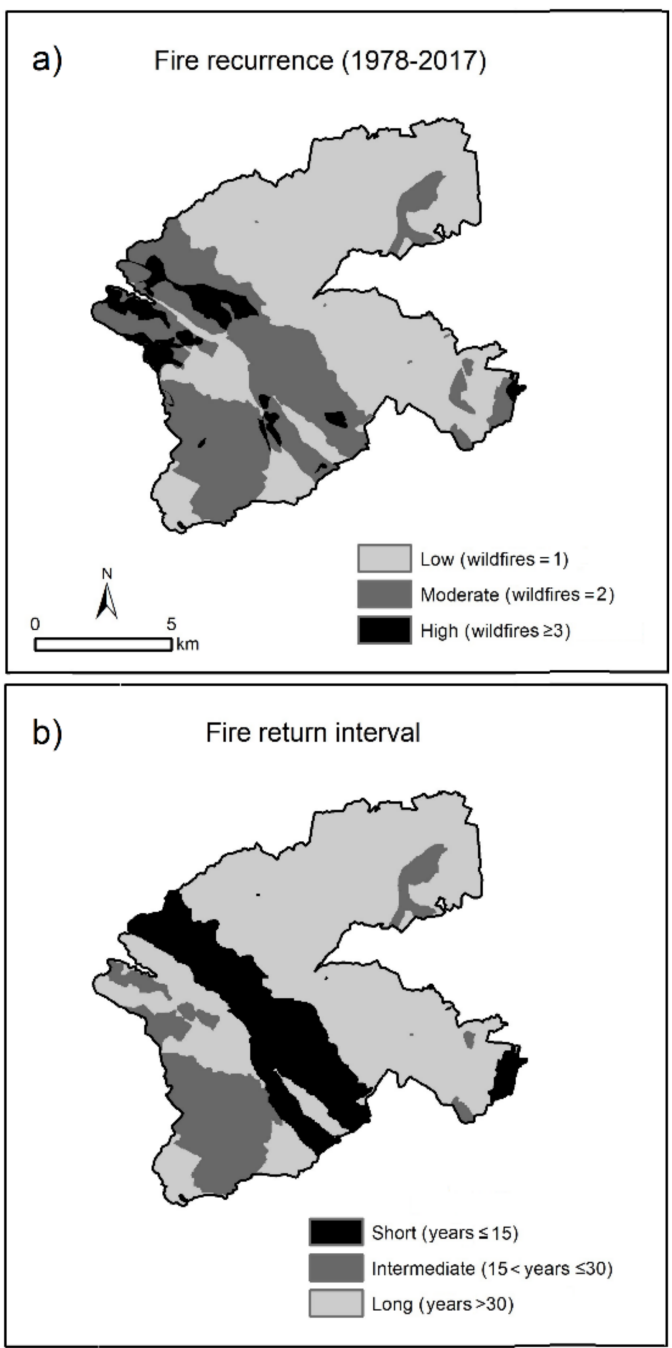

c) Burn severity

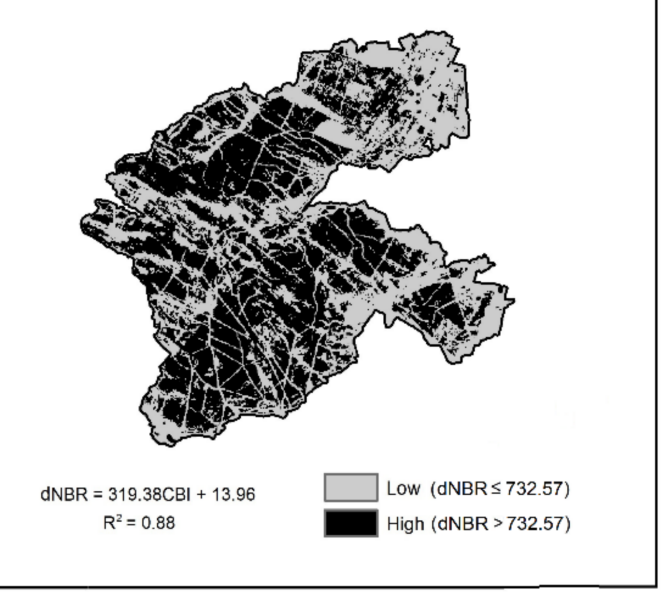

Figure 5. Spatial patterns of fire recurrence (total number of wildfires from 1978 to 2017) (a), fire return interval (number of years between the 2012 large wildfire and the preceding fire) (b), and burn severity of the 2012 large wildfire, measured by the difference of the Normalized Burn Ratio (dNBR) and classified according to the ground reference values of the Composite Burn Index (CBI) (c). The results of the linear regression between $\mathrm{dNBR}$ and CBI values for the 2012 large wildfire are also indicated. 
The correlation between the values of the spectral burn severity index (dNBR) and the ground burn severity index (CBI) was statistically significant $(p<0.05)$, with a high coefficient of determination $\left(R^{2}=0.88\right)$. For the most part $\left(61.02 \mathrm{~km}^{2}\right)$, the burn severity of the 2012 large wildfire was high (Figure 5c).

The combined fire regime attribute approach differentiated six fire recurrence-burn severity scenarios, with the low recurrence-low severity $\left(38.38 \mathrm{~km}^{2}\right)$ and low recurrence-high severity $\left(32.57 \mathrm{~km}^{2}\right)$ scenarios being the most extensive (Figure 6a). Correspondingly, there were six fire return interval-burn severity scenarios, with a spatial dominance of the areas with a long time-period between the 2012 large wildfire and the preceding fire, independently of burn severity (Figure 6b).
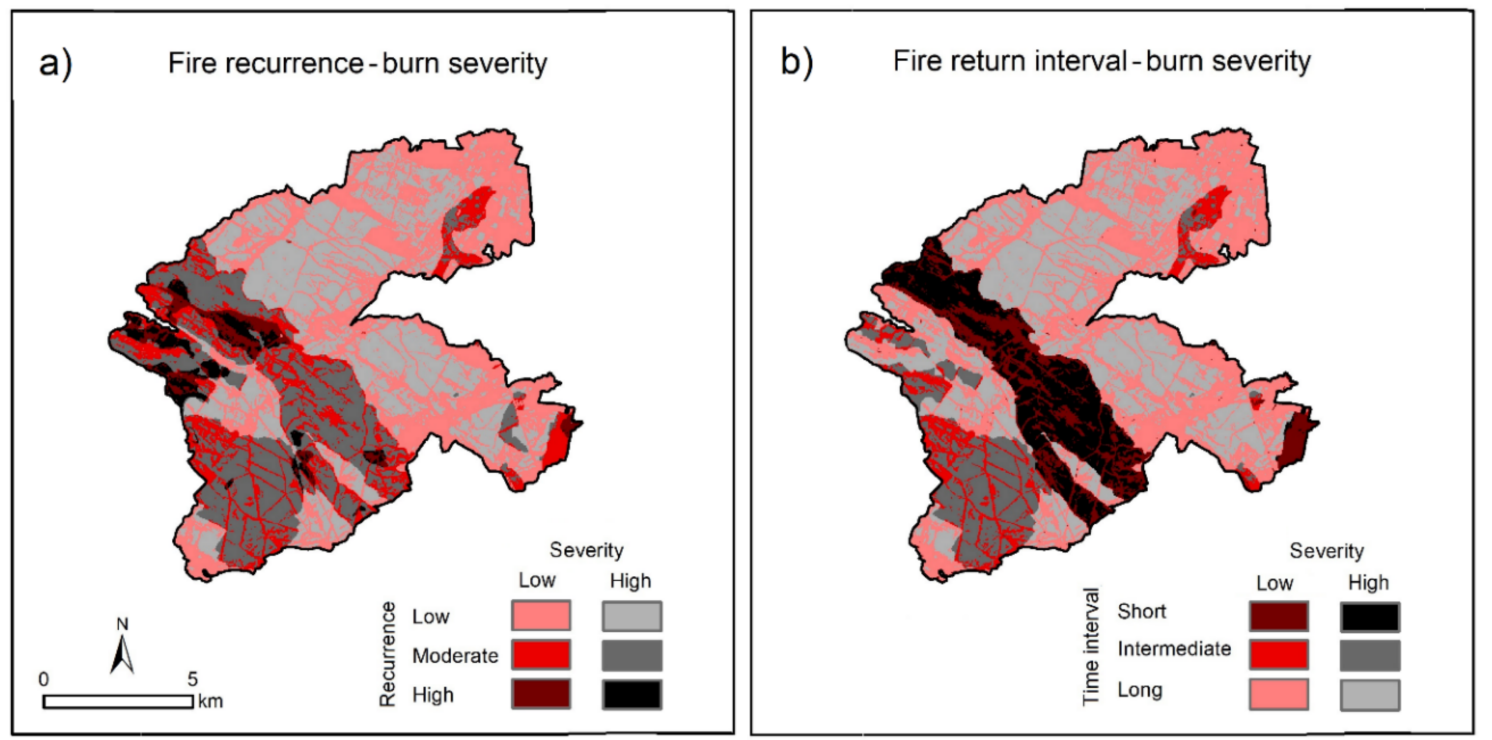

Figure 6. Combined fire regime attribute approach identifying the spatial patterns of the different fire recurrence-burn severity (a) and fire return interval-burn severity (b) scenarios. See Figure 5 for further information.

\subsection{Post-Fire Greenness Recovery}

The vegetation greenness over the short term ( 2 years after the 2012 large wildfire) was not recovered in any fire regime scenario (i.e., all dNDVI values $>0$ ) (Figure 7a). On average, the short-term dNDVI value of the fire scar was $0.59 \pm 0.11$ (mean \pm standard deviation), indicating low vegetation recovery 2 years after fire.

However, the post-fire recovery of vegetation greenness over the medium term (5 years after the 2012 large wildfire) was greater than over the short term $(0.10 \pm 0.08)$. It was found that $10.25 \%$ of the burned surface attained the greenness values of the pre-fire situation ( $d N D V I \leq 0.00)$ (Figure $7 \mathrm{~b}$ ) nonetheless, the remaining $89.75 \%$ of the surface had lower greenness values than the pre-fire situation (dNDVI $>0$ ). 
a) Post-fire greenness recovery (2014)

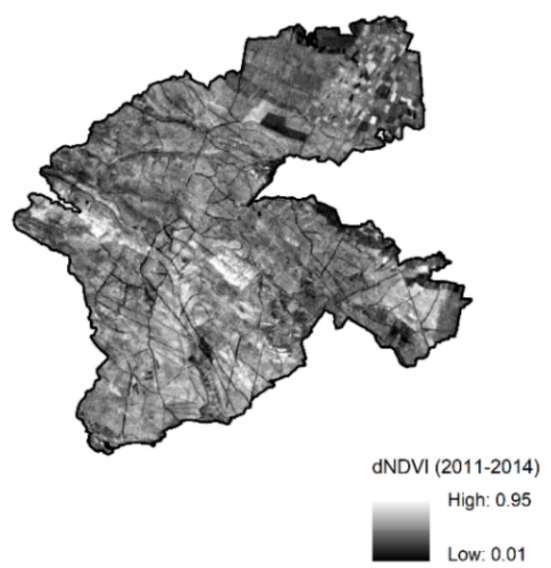

b) Post-fire greenness recovery (2017)

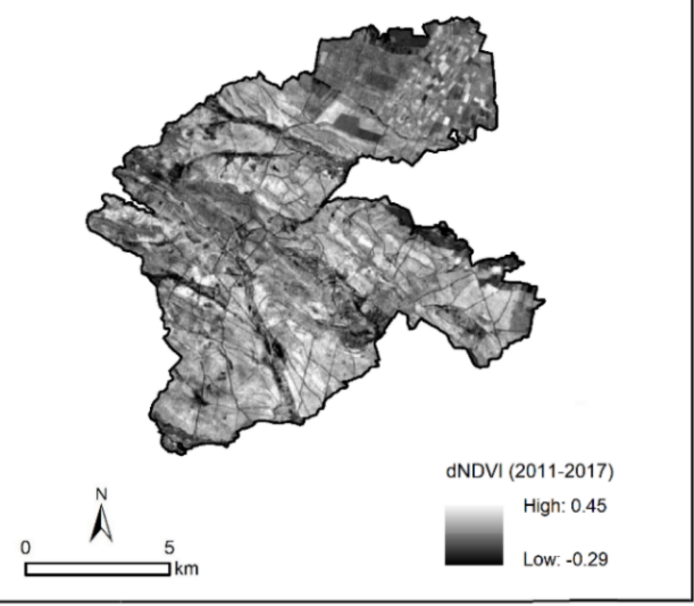

Figure 7. Spatial patterns of post-fire recovery of vegetation greenness over the short term (2 years) (a) and medium term (5 years) (b) after the 2012 large wildfire.

\subsection{Effects of Fire Regime Attributes on Post-Fire Greenness Recovery}

Every single and combined fire regime attribute had a statistically significant effect $(p<0.001)$ on the recovery of vegetation greenness (dNDVI), both over the short and medium term after the 2012 large wildfire (Table 1 ). The combined fire regime attributes always showed higher $R^{2}$ values than the single ones, indicating a higher explanatory capacity. In general, greenness recovery was greater (i.e., lower dNDVI values) over the medium than short term for the single and combined fire regime attributes (Figures 8 and 9).

The recovery of vegetation greenness was significantly greater in the high fire recurrence scenario both over the short (Figure 8a) and medium (Figure 8b) term. Nevertheless, during the study period, none of the fire recurrence categories was completely recovered.

Correspondingly, the short fire-return interval scenario had significantly higher vegetation greenness recovery over the short term (Figure 8c). This difference among fire-return interval categories was attenuated over the medium term, as both the short and long fire-return situations had similar values for greenness recovery (Figure $8 \mathrm{~d}$ ). However, none of the fire return interval categories attained the dNDVI values of the unburned situation.

Table 1. Results of the linear models ['anova()' outputs] showing the effects of the single and combined fire regime attributes (fire recurrence, fire return interval, burn severity, fire recurrence-burn severity and fire return interval-burn severity) on post-fire greenness recovery over the short [dNDVI (2011-2014)] and medium [dNDVI (2011-2017)] term after the 2012 fire. dNDVI = difference of the Normalized Difference Vegetation Index. Df $=$ degrees of freedom. Significant $p$-values are in bold face.

\begin{tabular}{cccccc}
\hline Response Variable & Predictor Variable & Df & $\boldsymbol{R}^{\mathbf{2}}$ & $\boldsymbol{F}$-value & $\boldsymbol{p}$-value \\
\hline dNDVI (2011-2014) & Fire recurrence & 3 & 0.348 & 177.522 & $<0.001$ \\
& Fire return interval & 3 & 0.352 & 180.058 & $<0.001$ \\
& Burn severity & 2 & 0.338 & 254.305 & $<0.001$ \\
& Fire recurrence-burn severity & 6 & 0.380 & 101.405 & $<0.001$ \\
& Fire return interval-burn severity & 6 & 0.394 & 107.361 & $<0.001$ \\
dNDVI (2011-2017) & Fire recurrence & 3 & 0.193 & 79.529 & $<0.001$ \\
& Fire return interval & 3 & 0.142 & 55.070 & $<0.001$ \\
& Burn severity & 2 & 0.272 & 186.045 & $<0.001$ \\
& Fire recurrence-burn severity & 6 & 0.313 & 75.279 & $<0.001$ \\
& Fire return interval-burn severity & 6 & 0.287 & 66.604 & $<0.001$ \\
\hline
\end{tabular}


Short term ( 2 years after the fire)
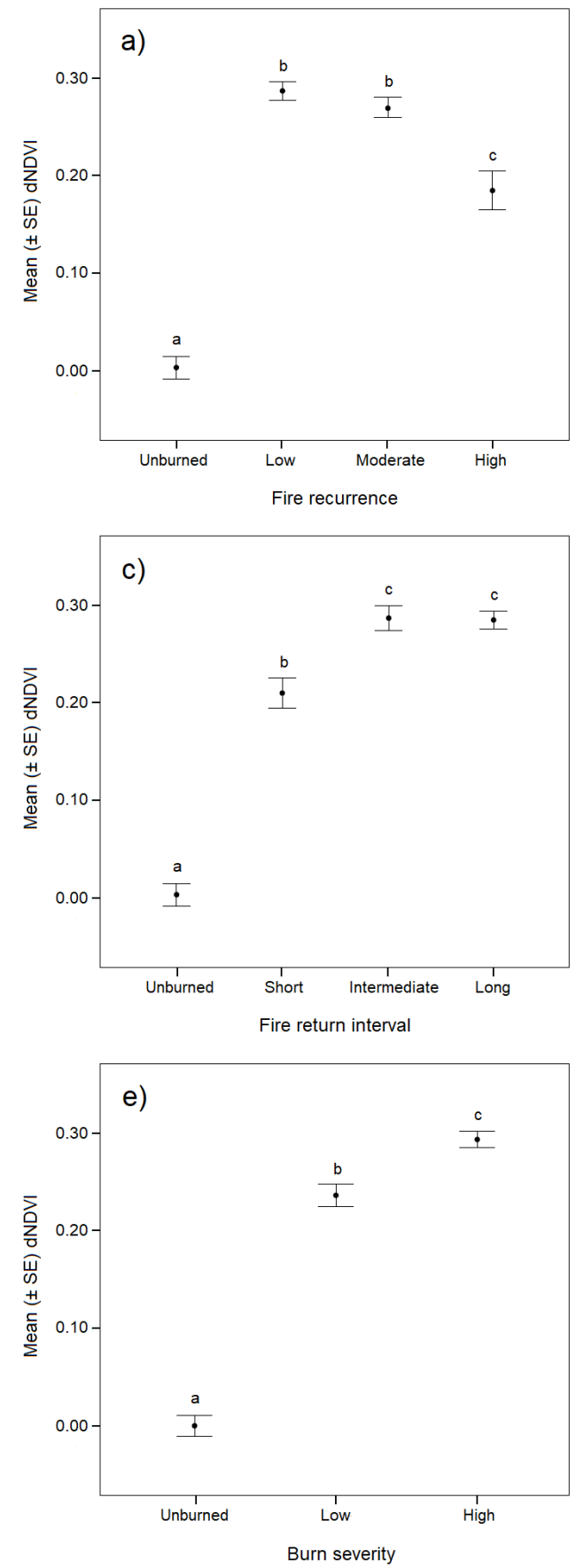

Medium term ( 5 years after the fire)

b)

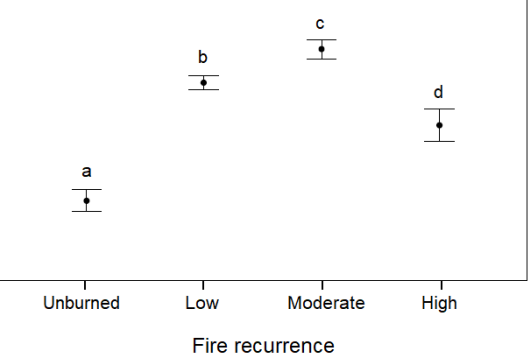

d)
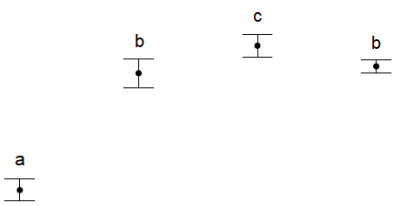

Unburned Short Intermediate Long

Fire return interval

f)
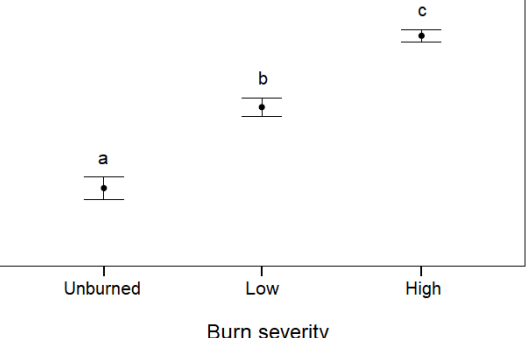

Figure 8. Mean ( \pm standard error) vegetation greenness values measured by the difference of the Normalized Difference Vegetation Index (dNDVI) over the short ( 2 years) and medium ( 5 years) term after the 2012 large wildfire for the different scenarios of fire recurrence (total number of wildfires from 1978 to 2017) (a,b), fire return interval (number of years between the 2012 large wildfire and the preceding fire) (c,d), and burn severity of the 2012 large wildfire as the difference of the Normalized Burn Ratio (dNBR) (e,f). Different letters above the error bars (a, b, c, d) denote statistically significant differences between mean values $(p<0.05)$. 

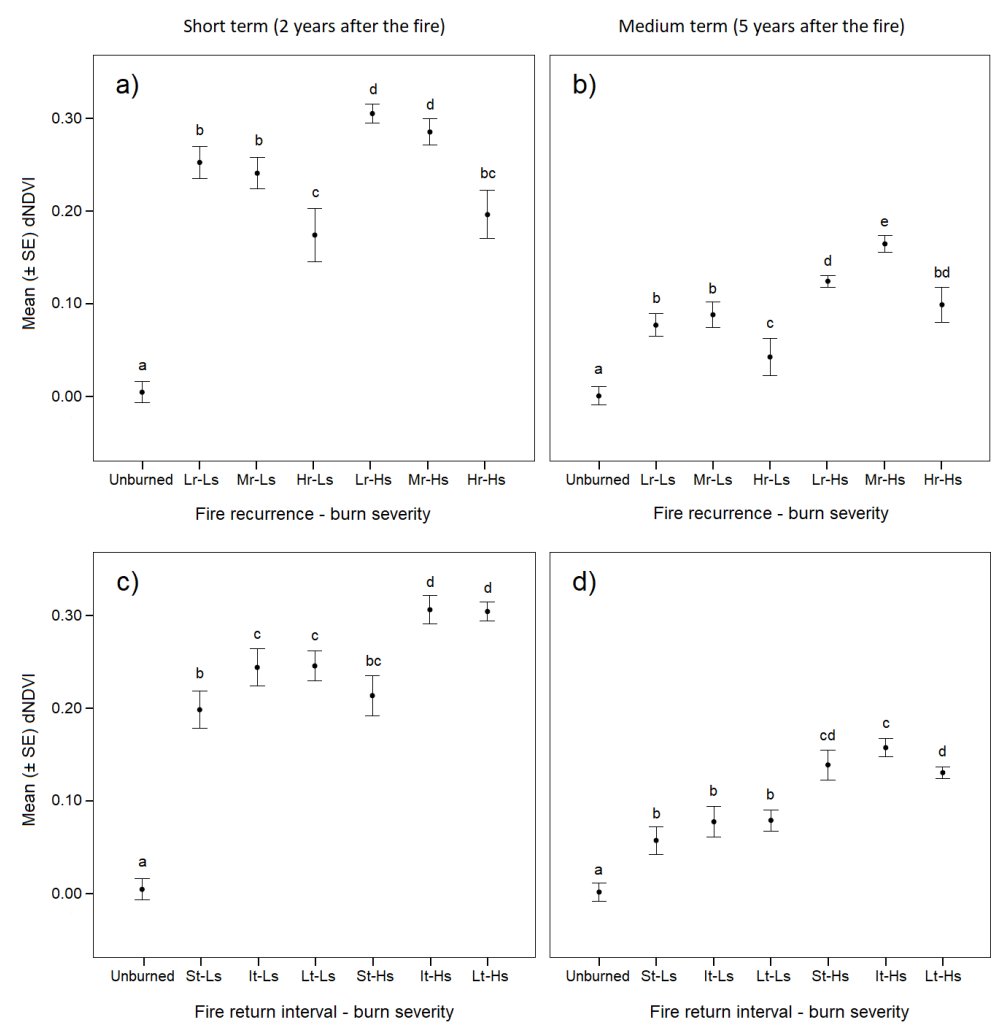

Figure 9. Mean ( \pm standard error) vegetation greenness values measured by the difference of the Normalized Difference Vegetation Index (dNDVI) over the short (2 years) and medium (5 years) term after the 2012 large wildfire for the different scenarios identified by the combined fire attribute approach: fire recurrence-burn severity $(\mathbf{a}, \mathbf{b})$, and fire return interval-burn severity (c,d). Lr, Mr, and $\mathrm{Hr}$ indicate low, moderate and high fire recurrence, respectively. Ls and Hs indicate low and high burn severity, respectively. St, It, and Lt indicate short, intermediate and long fire return interval. Different letters above the error bars $(a, b, c, d, e)$ denote statistically significant differences between mean values $(p<0.05)$. See Figure 8 for further information.

The burn severity of the 2012 large wildfire showed an inverse relationship with the recovery of vegetation greenness over the short (Figure 8e) and medium (Figure $8 \mathrm{f}$ ) term after fire (i.e., the low burn severity category had the greatest greenness recovery). Even so, the dNDVI values of both low and high burn severity classes were significantly higher than those of the unburned situation.

Generally, the combination of temporal (fire recurrence and fire return interval) and magnitude (burn severity) fire regime attributes resulted in wider ranges of greenness recovery values (Figure 9) than those obtained with single fire regime attributes (Figure 8). Also, the differences in greenness recovery between low and high burn severity categories over the short term were lessened when combined with either the high fire recurrence or short fire return interval (Figure 9a,c). Consequently, there were no statistically significant differences $(p \geq 0.05)$ in greenness recovery between $(1)$ high recurrence-low severity and high recurrence-high severity combinations (Figure 9a), and (2) short return interval-low severity and short return interval-high severity combinations (Figure 9c) 2 years after fire.

Focusing on fire recurrence-burn severity, the highest recovery of the vegetation greenness was attained at the high recurrence scenarios (high recurrence-low severity and high recurrence-high severity) over the short term (Figure 9a), and at the high recurrence-low severity scenario over the medium term (Figure 9b), which reached the closest dNDVI value to the unburned situation among all the analyzed single and combined fire regime scenarios (Figures 8 and 9). 
Similarly, on analysis of the fire return interval-burn severity, the greatest greenness recovery corresponded to the short fire-return interval scenarios (short interval-low severity and short interval-high severity) over the short term (Figure 9c), and to the three low severity combinations (short interval-low severity, intermediate interval-low severity, and long interval-low severity) over the medium term (Figure 9d).

\section{Discussion}

In this work, we have shown the utility of remote sensing tools to analyze fire regime attributes and their effects on vegetation greenness recovery after large wildfires. Landsat imagery and ancillary data were used to identify the 28 wildfires that occurred in a 40-year period (1978-2017) in Sierra del Teleno within the perimeter of the 2012 large fire, resulting in a spatially heterogeneous fire history and a wide range of post-fire greenness recovery. Our results demonstrated that all the fire regime attributes that were spatially characterized, whether they followed a single (fire recurrence, fire return interval, burn severity) or combined approach (fire recurrence-burn severity and fire return interval-burn severity), were significantly related to the post-fire recovery of vegetation greenness. However, the combination of fire recurrence or fire return interval with burn severity was able to identify a larger variety of scenarios of post-fire greenness recovery than the single approach, the combined attributes being the best predictors of post-fire recovery of vegetation greenness.

The fire scars analysis allowed us to identify the temporal evolution of fire size and number throughout the four studied decades in our specific study site. The results, which have to be interpreted considering the limited extent of the studied area and period, indicated a decrease in the number of fires and an increase in the extent of the burned area during the studied period. This is an opposite trend to that reported for Southern European countries and for Spain, where, in general, the average fire size has decreased and the number of fires has increased since the 1980s [62]. However, other authors have found different trends in particular regions within the Iberian Peninsula. For instance, Pausas [63] indicated an unclear trend for the size of the area burned in the Eastern Iberian Peninsula between 1968 and 2000, which was closely related to summer rainfall. The patterns of the increasing average size of fires in our study area could be explained by the contribution of the large wildfires that occurred in 1998 and 2012, which burned 31\% and 100\% of the study area, respectively. Furthermore, the fuel depletion caused by these two large fires could prevent subsequent wildfires during the following years, as fire occurrence in Mediterranean ecosystems is fuel-limited [64]. The occurrence of such large wildfires is increasing in some regions in the world $[11,65]$ and is relatively recent in Spain $[4,25]$, the study area being a good example.

The fire recurrences found in this study were consistent with those in other fire-prone pine forests within the Iberian Peninsula $[8,66]$ for a 25-year period or longer. Fire recurrence affected post-fire greenness recovery over the short and medium term post-fire, the high recurrence scenario being the most recovered. Recovery in the different fire recurrence scenarios can be explained by the vegetation composition in the pre-fire situation, because post-fire regeneration in P. pinaster ecosystems is via auto-succession [14,67]. In this sense, the areas classified as high recurrence were occupied mainly by shrubs and herbaceous species ( $4.53 \%$ pines, $36.89 \%$ shrubs, $38.13 \%$ grasses) [68], which are promoted by high recurrences and additionally, are rapidly recovered after fire $[22,67,69]$. Conversely, the low recurrence areas were predominantly covered by pines ( $57.53 \%$ pines, $13.25 \%$ shrubs, $19.16 \%$ grasses) [68], which require more time than shrubs to completely recover [70].

The fire return intervals in the study area ranged from $<15$ years to $>30$ years, being within the typical intervals reported for Mediterranean ecosystems (varying from 10 to up to more than 120 years) [1]. The areas burned in a short-return interval were more rapidly recovered than those burned in an intermediate and long interval, probably due to the dominance of shrubs $(6.72 \%$ pines, $38.80 \%$ shrubs, $32.11 \%$ grasses) [68]. In this sense, it is expected that shrubs such as those present in our study area (Ericaceae and Cistaceae) increase their dominance in short fire interval scenarios, optimal at fire intervals of 5 and 10 years, respectively [71]. Conversely, Mediterranean fire-prone pine 
forests have their optimum conditions at fire return intervals over 40 years, and only disappear when intervals are shorter than 5 years [71].

The burn severity obtained through the dNBR spectral index indicated that the large wildfire of 2012 was predominantly severe, with the low severity class confined to valleys, areas close to paths, and limits of the fire scar as previous studies pointed out [56,72]. P. pinaster forest ecosystems are frequently subjected to high severity fires, because they are highly flammable and prone to crown fires $[14,25,69]$. The relationships between burn severity and post-fire greenness recovery indicated that this fire regime attribute was a crucial factor over the short ( 2 years) and medium ( 5 years) term after the fire $[39,44,73]$. In low burn severity areas, greenness recovery was higher, because some pines (between 0 and 80\%) remained alive [33], and additionally, their canopy seed bank guaranteed seed dispersal over the medium term after fire [69]. The understory shrub community is also less affected in low severity scenarios, with a general survival rate of up to 80\% [36]. Conversely, in severely burned areas, pine and shrub mortality involves a significant canopy change [33,36]. This results in considerable changes in vegetation greenness after the fire. However, over that span of time (2-5 years), the ecosystem has shown a large recovery in both low and high severities, as other researchers have found [44]. This could be related to the high pine seedling establishment that follows crown fires in Mediterranean fire-prone forests such as those dominated by P. pinaster [4,69], and to the high resiliency of the present understory community, which can be completely recovered in 9 years even after severe disturbances [74].

The combined approach merging fire temporal (fire recurrence and fire return interval) and magnitude (burn severity) attributes represented a large variety of scenarios, being more representative than the other analyzed products of the high spatial heterogeneity, which is typical after large wildfires [11]. Among the identified scenarios, the two burn severity classes were well represented in the three fire recurrence and fire return interval scenarios. This result suggests that under the Mediterranean climatic conditions of the study site, even the high recurrence ( 3 or 4 fires in 40 years) and short fire interval ( $<15$ years) scenarios had fuel loads enough to originate high burn severity scenarios [2]. Moreover, the combined fire regime attributes were the best predictors of post-fire greenness recovery, and they differentiate more extreme situations than the single approach over the short and medium term after the fire, apparently due to the cumulative effect of the fire temporal and magnitude fire regime attributes. Thus, the fire recurrence-burn severity and fire return interval-burn severity classification showed the most affected scenarios and the closest scenarios to the unburned situation.

Our study shows the possibility of carrying out integral assessments of fire regime attributes (spatial, temporal and magnitude) using remote sensing methods, and indicates a high predictive capacity of fire regime attributes (temporal, magnitude and combined) for post-fire greenness recovery after large wildfires in fire-prone pine ecosystems. This information can help managers to predict the post-fire greenness recovery capacity of fire-prone P. pinaster forests according to their specific fire regime, and therefore could be used to adopt the appropriate management strategies aimed at reverting to the pre-fire status in each scenario [5].

In order to generalize our results, we encourage conducting future studies analyzing the relationship between fire regime attributes and post-fire greenness recovery in other wildfires and in different regions. Studies in other types of ecosystems are also recommendable, because the resilience of the communities can vary considerably [75]. We also highlight the importance of differentiating the structure and composition of the vegetation [23] for a better understanding of greenness recovery after different fire regime scenarios in fire-prone pine forests in the Mediterranean Basin.

\section{Conclusions}

The spatial, temporal and magnitude attributes of a fire regime are important driving factors in the post-fire recovery of Mediterranean pine ecosystems, especially in areas subjected to increasingly more extensive recurrent fires $[14,18,76]$. Under the growing complexity of wildfire regimes, our 
findings demonstrated that integrating temporal (fire recurrence and return interval) and magnitude (burn severity) attributes using remote sensing methods allows for a more realistic identification of the most favorable scenarios for vegetation greenness recovery after fire, relative to the typical single fire regime attribute analysis of most research. This novel combined attribute approach evidenced that high fire recurrence and short fire return interval combinations with any category of burn severity (low or high) attained the greatest recovery of vegetation greenness over the short term (2 years after the most recent large (> 500 ha) fire). Whereas the high fire recurrence-low burn severity situation, and the low severity combinations with any category of fire return interval (short, intermediate or long) were the most propitious scenarios for greenness recovery over the medium term ( 5 years after fire). Moreover, the results of the spatial analysis of the different combined scenarios using remote sensing methods highlighted the outstanding heterogeneity in the post-fire greenness recovery of pine ecosystems subjected to an intricate reality of fire regimes with varying attributes over vast burned areas. This information will be highly valuable to forest managers facing the consequences of even more acute fire regimes, as it will aid the implementation of effective restoration actions in extensively burned areas when the main restoration goal is the full recovery of vegetation greenness. Nonetheless, we encourage future remote sensing studies aimed at a better understanding of the impact of combined fire regime attributes on post-fire greenness recovery in fire-prone pine ecosystems that further integrate the spatial variation of pre-fire vegetation [23].

Author Contributions: V.F.-G., C.Q., E.M., L.C. and A.F.-M. conceived and designed the experiment; V.F.-G., C.Q., E.M., L.C. and A.F.-M. obtained the data, V.F.-G. and A.T. analyzed the data; V.F.-G., A.T. and L.C. wrote the paper with contributions of C.Q., E.M. and A.F.-M.; L.C. and A.F.-M. advised and coordinated the study.

Acknowledgments: This study was financially supported by the Spanish Ministry of Economy and Competitiveness, and the European Regional Development Fund (ERDF), in the framework of the GESFIRE (AGL2013-48189-C2-1-R) and FIRESEVES (AGL2017-86075-C2-1-R) projects; and by the Regional Government of Castilla y León within the framework of the FIRECYL (LE033U14) and SEFIRECYL (LE001P17) projects. V.F.-G. was supported by a predoctoral fellowship from the Spanish Ministry of Education (FPU14/00636).

Conflicts of Interest: The authors declare no conflict of interest.

\section{References}

1. Thonicke, K.; Venevsky, S.; Sitch, S.; Cramer, W. The role of fire disturbance for global vegetation dynamics: Coupling fire into a Dynamic Global Vegetation Model. Glob. Ecol. Biogeogr. 2001, 10, 661-677. [CrossRef]

2. Bond, W.J.; Keeley, J.E. Fire as a global 'herbivore': The ecology and evolution of flammable ecosystems. Trends Ecol. Evol. 2005, 20, 387-394. [CrossRef] [PubMed]

3. Chuvieco, E. Remote Sensing of Large Wildfires in the European Mediterranean Basin; Springer: Berlin, Germany, 1999; pp. 1-212. ISBN 978-3-642-60164-44.

4. Pausas, J.G.; Llovet, J.; Rodrigo, A.; Vallejo, R. Are wildfires a disaster in the Mediterranean basin?-A review. Int. J. Wildland Fire 2008, 17, 713-723. [CrossRef]

5. Moreira, F.; Arianoutsou, M.; Corona, P.; De las Heras, J. Post-Fire Management and Restoration of Southern European Forests, Managing Forest Ecosystems; Springer Science + Business Media B.V.: Dordrecht, The Netherlands, 2012; pp. 1-319. ISBN 978-94-007-2208-8.

6. Richardson, D.M. Ecology and Biogeography of Pinus; Cambridge University Press: Cambridge, UK, 2000; pp. 1-527. ISBN 0521789109.

7. Tapias, R.; Climent, J.; Pardos, J.A.; Gil, L. Life histories of Mediterranean pines. Plant Ecol. 2004, 171, 53-68. [CrossRef]

8. Röder, A.; Hill, J.; Duguy, B.; Alloza, J.A.; Vallejo, R. Using long time series of Landsat data to monitor fire events and post-fire dynamics and identify driving factors. A case study in the Ayora region (eastern Spain). Remote Sens. Environ. 2008, 112, 259-273. [CrossRef]

9. Bergeron, Y.; Leduc, A.; Harvey, B.D.; Gauthier, S. Natural fire regime: A guide for sustainable management of the Canadian boreal forest. Silva Fenn. 2002, 36, 81-95. [CrossRef]

10. Van Wagtendonk, J.W.; Lutz, J.A. Fire Regime Attributes of Wildland Fires in Yosemite National Park, USA. Fire Ecol. 2007, 3, 34-52. [CrossRef] 
11. Turner, M.G. Disturbance and landscape dynamics in a changing world. Ecology 2010, 91, $2833-2849$. [CrossRef] [PubMed]

12. Eugenio, M.; Verkaik, I.; Lloret, F.; Espelta, J.M. Recruitment and growth decline in Pinus halepensis populations after recurrent wildfires in Catalonia (NE Iberian Peninsula). For. Ecol. Manag. 2006, 231, 47-54. [CrossRef]

13. Espelta, J.M.; Verkaik, I.; Eugenio, M.; Lloret, F. Recurrent wildfires constrain long-term reproduction ability in Pinus halepensis Mill. Int. J. Wildland Fire 2008, 17, 579-585. [CrossRef]

14. Fernandes, P.M.; Rigolot, E. The fire ecology and management of maritime pine (Pinus pinaster Ait.). For. Ecol. Manag. 2007, 241, 1-13. [CrossRef]

15. Keeley, J.E. Resilience of Mediterranean shrub communities to fires. In Resilience in Mediterranean-Type Ecosystems; Dell, B., Hopkins, A.J.M., Lamont, B.B., Eds.; Springer: Dordrecht, The Netherlands, 1986; pp. 95-112. ISBN 978-94-009-4822-8.

16. Calvo, L.; Baeza, J.; Marcos, E.; Santana, V.; Papanastasis, V.P. Post-Fire management of shrublands. In Post-Fire Management and Restoration of Southern European Forests, Managing Forest Ecosystems; Moreira, F., Arianoutsou, M., Corona, P., De las Heras, J., Eds.; Springer Science + Business Media B.V.: Dordrecht, The Netherlands, 2012; pp. 293-319. ISBN 978-94-007-2208-8.

17. Tapias, R.; Gil, L.; Fuentes-Utrilla, P.; Pardos, J.A. Canopy seed banks in Mediterranean pines of southeastern Spain: A comparison between Pinus halepensis Mill., P. pinaster Ait., P. nigra Arn. and P. pinea L. J. Ecol. 2001, 89, 629-638. [CrossRef]

18. González-De Vega, S.; de las Heras, J.; Moya, D. Resilience of Mediterranean terrestrial ecosystems and fire severity in semiarid areas: Responses of Aleppo pine forests in the short, mid and long term. Sci. Total Environ. 2016, 573, 1171-1177. [CrossRef] [PubMed]

19. Keeley, J.E. Fire intensity, fire severity and burn severity: A brief review and suggested usage. Int. J. Wildland Fire 2009, 18, 116-126. [CrossRef]

20. Francos, M.; Úbeda, X.; Tort, J.; Panareda, J.M.; Cerdà, A. The role of forest fire severity on vegetation recovery after 18 years. Implications for forest management of Quercus suber L. in Iberian Peninsula. Glob. Planet. Chang. 2016, 145, 11-16. [CrossRef]

21. Zavala, L.M.; De Celis, R.; Jordán, A. How wildfires affect soil properties. A brief review. Geogr. Res. Lett. 2014, 40, 311-331. [CrossRef]

22. Taboada, A.; Tárrega, R.; Marcos, E.; Valbuena, L.; Suárez-Seoane, S.; Calvo, L. Fire recurrence and emergency post-fire management influence seedling recruitment and growth by altering plant interactions in fire-prone ecosystems. For. Ecol. Manag. 2017, 402, 63-75. [CrossRef]

23. Yang, J.; Pan, S.; Dangal, S.; Zhang, B.; Wang, S.; Tian, H. Continental-scale quantification of post-fire vegetation greenness recovery in temperate and boreal North America. Remote Sens. Environ. 2017, 199, 277-290. [CrossRef]

24. Krasnow, K.; Fry, D.I.; Stephens, S.T. Spatial, temporal and latitudinal components of historical fire regimes in mixed conifer forests, California. J. Biogeogr. 2017, 44, 1239-1253. [CrossRef]

25. Pausas, J.G.; Fernández-Muñoz, S. Fire regime changes in the Western Mediterranean Basin: From fuel-limited to drought-driven fire regime. Clim. Chang. 2012, 110, 215-226. [CrossRef]

26. Meddens, A.H.H.; Kolden, C.A.; Lutz, J.A. Detecting unburned areas within wildfire perimeters using Landsat and ancillary data across the northwestern United States. Remote Sens. Environ. 2016, 186, 275-285. [CrossRef]

27. Soulard, C.E.; Albano, C.M.; Villareal, M.L.; Walker, J.J. Continuous 1985-2012 Landsat Monitoring to Assess Fire Effects on Meadows in Yosemite National Park, California. Remote Sens. 2016, 8, 371. [CrossRef]

28. Hawbaker, T.J.; Vanderhoof, M.K.; Beal, Y.; Takacs, J.D.; Schmidt, G.L.; Falgout, J.T.; Williams, B.; Fairaux, N.M.; Caldwell, M.K.; Picotte, J.J.; et al. Mapping burned areas using dense time-series of Landsat data. Remote Sens. Environ. 2017, 198, 504-522. [CrossRef]

29. USGS. Landsat Missions. Available online: https://landsat.usgs.gov/ (accessed on 1 February 2018).

30. Bowman, D.M.J.S.; Zhang, Y.; Walsh, A.; Williams, R.J. Experimental comparison of four remote sensing techniques to map tropical savanna fire-scars using Landsat-TM imagery. Int. J. Wildland Fire, 2003, 12, 341-348. [CrossRef] 
31. Bastarrika, A.; Alvarado, M.; Artano, K.; Martinez, M.P.; Mesanza, A.; Torre, L.; Ramo, R.; Chuvieco, E. BAMS: A Tool for Supervised Burned Area Mapping Using Landsat Data. Remote Sens. 2014, 6, 12360-12380. [CrossRef]

32. Key, C.H. Ecological and sampling constraints on defining landscape fire severity. Fire Ecol. 2006, 2, 34-59. [CrossRef]

33. Fernández-García, V.; Santamarta, M.; Fernández-Manso, A.; Quintano, C.; Marcos, E.; Calvo, L. Burn severity metrics in fire-prone pine ecosystems along a climatic gradient using Landsat imagery. Remote Sens. Eviron. 2018, 206, 205-217. [CrossRef]

34. Chu, T.; Guo, X. Remote sensing techniques in monitoring post-fire effects and patterns of forest recovery in boreal forest regions: A review. Remote Sens. 2014, 6, 470-520. [CrossRef]

35. Parks, S.A.; Dillon, G.K.; Miller, C. A new metric for quantifying burn severity: The relativized burn ratio. Remote Sens. 2014, 6, 1827-1844. [CrossRef]

36. Key, C.H.; Benson, N.C. Landscape assessment (LA) sampling and analysis methods. In FIREMON: Fire Effects Monitoring and Inventory System; General Technical Report RMRS-GTR-164; USDA Forest Service: Washington, DC, USA, 2006; pp. 1-51.

37. Miller, J.D.; Thode, A.E. Quantifying burn severity in a heterogeneous landscape with a relative version of the delta normalized burn ratio (dNBR). Remote Sens. Environ. 2007, 109, 66-80. [CrossRef]

38. Díaz-Delgado, R.; Lloret, F.; Pons, X. Influence of fire severity on plant regeneration by means of remote sensing imagery. Int. J. Remote Sens. 2003, 24, 1751-1763. [CrossRef]

39. Viana-Soto, A.; Aguado, I.; Martínez, S. Assessment of Post-Fire Vegetation Recovery Using Fire Severity and Geographical Data in the Mediterranean Region (Spain). Environments 2017, 4, 90. [CrossRef]

40. Donato, D.C.; Fontaine, J.B.; Robinson, W.D.; Kauffmann, J.B.; Law, B.E. Vegetation response to a short interval between high-severity wildfires in a mixed-evergreen forest. J. Ecol. 2009, 97, 142-154. [CrossRef]

41. Stephens, S.L.; Agee, J.K.; Fulé, P.Z.; North, M.P.; Romme, W.H.; Swetnam, T.W.; Turner, M.G. Managing Forests and Fire in Changing Climates. Science 2013, 342, 41-42. [CrossRef] [PubMed]

42. Broncano, M.J.; Retana, J. Topography and forest composition affecting variability in fire severity and post-fire regeneration occurring after a large fire in the Mediterranean basin. Int. J. Wildland Fire, 2004, 13, 341-348. [CrossRef]

43. Wittenberg, L.; Malkinson, D.; Beeri, O.; JHalutzy, A.; Tesler, N. Spatial and temporal patterns of vegetation recovery following sequences of forest fires in a Mediterranean landscape, Mt. Carmel Israel. Catena 2007, 71, 76-83. [CrossRef]

44. Fernandez-Manso, A.; Quintano, C.; Roberts, D. Burn severity influence on post-fire vegetation cover resilience from Landsat MESMA fraction images time series in Mediterranean forest ecosystems. Remote Sens. Environ. 2016, 184, 112-123. [CrossRef]

45. Rouse, J.W.; Haas, R.H.; Schell, J.A.; Deering, D.W. Monitoring vegetation systems in the great plains with ERTS. In Proceedings of the Third ERTS Symposium, Washington, DC, USA, 10-14 December 1973; NASA: Washington, DC, USA, 1973; pp. 309-317.

46. Chuvieco, E. Teledetección ambiental. La observación de la Tierra desde el espacio; Ariel: Barcelona, Spain, 2010; pp. 1-590. ISBN 978-84-344-3498-1.

47. Malak, D.A.; Pausas, J.P. Fire regime and post-fire Normalized Difference Vegetation Index changes in the eastern Iberian peninsula (Mediterranean basin). Int. J. Wildland Fire 2006, 15, 407-413. [CrossRef]

48. Santamaría, J.E. El Pino Pinaster de la Sierra del Teleno. Historia, Ordenación, Crecimiento y Producción. Ph.D. Thesis, University of León, León, Spain, 2015.

49. GEODE. Cartografía Geológica Digital Continua a Escala 1:50.000. Available online: http://info.igme.es/ cartografiadigital/geologica/Geode.aspx (accessed on 1 February 2018).

50. Air Temperature and Precipitation (1971-2000). Iberian Climate Atlas; Agencia Estatal de Meteorologia, Ministerio de Medio Ambiente y Medio Rural y Marino; Instituto de Meteorologia de Portugal: Lisbon, Portugal, 2011; pp. 1-80. ISBN 978-84-7837-079-5.

51. Ninyerola, M.; Pons, X.; Roure, J.M. Atlas Climático Digital de la Península Ibérica. Metodología y Aplicaciones en Bioclimatología y Geobotánica; Universidad Autónoma de Barcelona: Bellaterra, Spain, 2005; pp. 1-44. ISBN 932860-8-7.

52. Esri España. ArcGIS. Available online: http://www.esri.es/arcgis/ (accessed on 1 February 2018). 
53. Ministerio de Agricultura y Pesca. Alimentación y Medio Ambiente. Available online: http:/ /www.mapama. gob.es/es/ (accessed on 1 February 2018).

54. Miller, J.D.; Yool, S.R. Mapping forest post-fire canopy consumption in several overstory types using multi-temporal Landsat TM and ETM data. Remote Sens. Environ. 2002, 82, 481-496. [CrossRef]

55. Ali, S.M.; Salman, S.S. Chronological Calibration Methods for Landsat Satellite Images. J. Appli. Phys. 2015, 7, 107-105. [CrossRef]

56. Quintano, C.; Fernández-Manso, A.; Calvo, L.; Marcos, E.; Valbuena, L. Land Surface temperature as potential indicator of burn severity in forest Mediterranean ecosystems. Int. J. Appl. Earth Obs. Geoinfor. 2015, 36, 1-12. [CrossRef]

57. Hope, A.; Tague, C.; Clark, R. Characterizing post-fire vegetation recovery of California chaparral using TM/ETM+ time-series data. Int. J. Remote Sens. 2007, 28, 1339-1354. [CrossRef]

58. Quintano, C.; Fernández-Manso, A.; Roberts, D.A. Multiple Endmember Spectral Mixture Analysis (MESMA) to map burn severity levels from Landsat images in Mediterranean countries. Remote Sens. Environ. 2013, 136, 76-88. [CrossRef]

59. Diniz-Filho, J.A.F.; Siqueira, T.; Padial, A.A.; Rangel, T.F.; Landeiro, V.L.; Bini, L.M. Spatial autocorrelation analysis allows disentangling the balance between neutral and niche processes in metacommunities. Oikos 2011, 121, 201-210. [CrossRef]

60. R Core Team. R: A Language and Environment for Statistical Computing. R Foundation for Statistical Computing. 2017. Available online: http://www.R-project.org/ (accessed on 1 October 2017).

61. Bivand, R.; Piras, G. Comparing Implementations of Estimation Methods for Spatial Econometrics. J. Stat. Softw. 2015, 63, 1-36. [CrossRef]

62. San-Miguel-Ayanz, J.; Durrant, T.; Boca, R.; Libertà, G.; Bocacci, F.; Di Leo, M.; López-Pérez, J.; Schulte, E. Forest Fires in Europe, Middle East and North Africa 2015; EUR 28158EN, Joint Research Center of the European Commission Technical Reports; EU Publications: Luxembourg, 2016. [CrossRef]

63. Pausas, J.G. Changes in fire and climate in the Eastern Iberian Peninsula (Mediterranean Basin). Clim. Chang. 2004, 63, 337-350. [CrossRef]

64. Pausas, J.G.; Paula, S. Fuel shapes the fire-climate relationship: Evidence from Mediterranean ecosystems. Global Ecol. Biogeogr. 2012, 21, 1074-1082. [CrossRef]

65. Bowman, D.M.J.S.; Williamson, G.J.; Abatzoglou, J.T.; Kolden, C.A.; Cochrane, M.A.; Smith, A.M. Human exposure and sensitivity to globally extreme wildfire events. Nat. Ecol. Evol. 2017, 1, 0058. [CrossRef] [PubMed]

66. Lucas-Borja, M.E.; Ahrazem, O.; Candel-Pérez, D.; Moya, D.; Fonseca, T.; Hernández Teclés, E.; De las Heras, J.; Gómez-Gómez, L. Evaluation of fire recurrence effect on genetic diversity in maritime pine (Pinus pinaster Ait.) stands using Inter-Simple Sequence Repeat profiles. Sci. Total Environ. 2016, 572, 1322-1328. [CrossRef] [PubMed]

67. Tessler, N.; Sapir, Y.; Witenberg, L.; Greenbaum, N. Recovery of Mediterranean vegetation after recurrent forest fires: Insight from the 2010 forest fire on Mount Carmel, Israel. Land Degrad. Dev. 2016, 27, 1424-1431. [CrossRef]

68. SIOSE. Sistema de Información sobre Ocupación del Suelo de España, 2011. Available online: http:/ / www. siose.es / (accessed on 1 February 2018).

69. Calvo, L.; Santalla, S.; Valbuena, L.; Marcos, E.; Tárrega, R.; Luis-Calabuig, E. Post-fire natural regeneration of a Pinus pinaster forest in NW Spain. Plant Ecol. 2008, 197, 81-90. [CrossRef]

70. Rodrigo, A.; Retana, J.; Picó, F.X. Direct regeneration is not the only response of Mediterranean forests to large fires. Ecology 2004, 85, 716-729. [CrossRef]

71. Pausas, J.G. Response of plant functional types to changes in the fire regime in Mediterranean ecosystems: A simulation approach. J. Veg. Sci. 1999, 10, 717-722. [CrossRef]

72. Quintano, C.; Fernandez-Manso, A.; Roberts, D.A. Burn severity mapping from Landsat MESMA fraction images and Land Surface Temperature. Remote Sens. Environ. 2017, 190, 83-95. [CrossRef]

73. Maia, P.; Pausas, J.G.; Vasques, A.; Keizer, J.J. Fire severity as a key factor in post-fire regeneration of Pinus pinaster (Ait.) in Central Portugal. Ann. For. Sci. 2012, 69, 489-498. [CrossRef]

74. Calvo, L.; Tárrega, R.; de Luis, E. Secondary succession after perturbations in a shrubland community. Acta Oecol. 2002, 23, 393-404. [CrossRef] 
75. Johnstone, J.F.; Allen, C.D.; Franklin, J.F.; Frelich, L.E.; Harvey, B.J.; Higuera, P.E.; Mack, M.C.; Meentemeyer, R.K.; Metz, M.R.; Perry, G.L.W.; et al. Changing disturbance regimes, ecological memory, and forest resilience. Front. Ecol. Environ. 2016, 14, 369-378. [CrossRef]

76. Moreira, F.; Viedma, O.; Arianoutsou, M.; Curt, T.; Koutsias, N.; Rigolot, E.; Barbati, A.; Corona, P.; Vaz, P.; Xanthopoulos, G.; et al. Landscape-wildfire interactions in southern Europe: Implications for landscape management. J. Environ. Manag. 2011, 92, 2389-2402. [CrossRef] [PubMed]

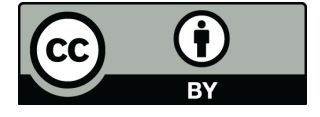

(C) 2018 by the authors. Licensee MDPI, Basel, Switzerland. This article is an open access article distributed under the terms and conditions of the Creative Commons Attribution (CC BY) license (http:/ / creativecommons.org/licenses/by/4.0/). 